\title{
Infestation of wild boar meat from the Eastern Lublin province with Alaria mesocercariae
}

\author{
NATALIA STROKOWSKA ${ }^{1}$, ZBIGNIEW BEŁKOT ${ }^{2}$, JAN WIŚNIEWSKI ${ }^{1}$, MAREK NOWICKI $^{1}$,

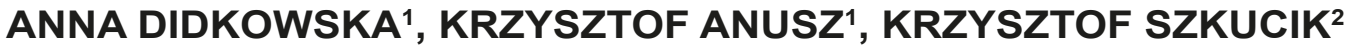 \\ 1Department of Food Hygiene and Public Health Protection, Faculty of Veterinary Medicine, \\ Warsaw University of Life Sciences, Nowoursynowska 159, 02-776 Warsaw, Poland \\ ${ }^{2}$ Department of Food Hygiene of Animal Origin, Faculty of Veterinary Medicine, \\ University of Life Sciences in Lublin, Akademicka 12, 20-033 Lublin, Poland
}

Strokowska N., Bełkot Z., Wiśniewski J., Nowicki M., Didkowska A., Anusz K., Szkucik K. Infestation of wild boar meat from the Eastern Lublin province with Alaria mesocercariae

Summary

The study was aimed at assessment of the usefulness of a digestion method, a standard procedure for routine examination of wild boar meat for Trichinella, in detecting the presence of Distomum musculorum suis (DMS) in the population of wild boars from the Eastern Lublin province. The study material included 500 samples collected from the diaphragm pillars of 250 young boars (6-12 months) and 250 boars above one year of age. First, the meat was tested with the digestion method that is a referential procedure for trichinosis detection. Then, the samples in which over ten mesocercariae were found were assessed with an Alaria-Migration Technique (AMT). The digestion method confirmed the presence of Alaria mesocercariae in 42 carcasses of young boars $(\mathbf{1 6 . 8 \%})$ and 117 samples of animals older than one year $(\mathbf{4 6 . 8 \% )}$. The study showed a diversified intensity of the parasite presence in the carcasses of individual animals. The invasion intensity ranged from 1 to 18 parasites in $50 \mathrm{~g}$ of meat in the young animals, and from 1 to 22 larvae in the older individuals. The carcasses of eight young and thirty two older animals contained over 10 parasites per $50 \mathrm{~g}$ of the meat, which accounted for $3.2 \%$ and $\mathbf{1 2 . 8 \%}$ animals per respective age group. AMT analysis also indicated variable intensity of the parasite infestation, amounting to 32-57 mesocercariae in young animals and 31-71 larvae in the older ones. The study demonstrated an almost three times higher efficiency of the AMT method than the digestion method, which made us conclude that the former should be recommended for Alaria detection. The digestion method used for routine detection of Trichinella, despite its lower accuracy in diagnosing Alaria mesocercariae, can be also employed for the detection of DMS in the case of intensive parasite infection. Our study confirmed high prevalence of the parasite among wild boars from the Eastern Lublin Province. We also found that the invasion intensity depended on the animal age and was higher in older individuals. Considering the zoonotic nature of alariosis and its frequency, it poses an increasingly common problem for official veterinarians during the sanitary and veterinary evaluation of wild boar meat.

Keywords: wild boar meat, Alaria mesocercariae, Distomum musculorum suis, Trichinella digestion method, Alaria-Migration Technique

The trematodes of the Alaria genus are parasites of many wild and domestic carnivores, mainly foxes, wolves, raccoons, dogs and cats $(3,10,12,16,18$, $34,37)$. The parasite has a complex life cycle with two intermediate hosts. The final host excretes noninvasive eggs with the feces; after incubation, these eggs hatch into miracidia that actively search for the first intermediate host, i.e. the freshwater snail common ramshorn (Planorbis planorbis) or Whirlpool ramshorn (Anisus vortex) (26). In the snail's body the parasite passes through further stages of development, i.e. mother sporocysts, daughter sporocysts, embryoid bodies, and finally furcocercariae. The furcocercariae then leave the snail and actively infect another intermediate host, i.e. a tadpole or imago of European frog (Rana temporaria) or moor frog (Rana terrestris) (23, 39). In the body of the second intermediate host, the parasite develops into the invasive forms that attack the final host, i.e. mesocercariae $(5,17)$. The life cycle of Alaria trematodes can also be realized in many paretic (atypical) hosts that allow the species to survive if there are not enough typical hosts. Within this group, special attention should be paid to the wild boar (Sus scrofa) - an omnivore that can eat other intermediate 
hosts (snails, tadpoles, frogs), or the carrion of other paretic hosts (mice, rats, polecats, martens, raccoons) as an opportunist $(19,21,22,27,28,33)$. Its habitats (forest biotopes with numerous wetlands) also make wild boar a frequent, though atypical, host in the life cycle of Alaria trematodes.

If the parasite develops in a paretic host, the mesocercariae are not further transformed but undergo secondary encystation and retain their full infectious capability. When consumed by a wild boar, mesocercariae usually migrate from the gastrointestinal tract to the periomental fat, connective or muscular tissue, where they are referred to in the public health nomenclature as Distomum musculorum suis (DMS). At this developmental stage, the parasite can be found accidentally during an official examination of wild boar meat for Trichinella. With a significant increase in the number of foxes as final hosts and wild boars as paretic hosts (Fig. 1), the incidence of confirmed cases of alariosis, detected during the routine examination of wild boar meat for Trichinella, has grown considerably over the past few years.

The magnetic stirrer digestion method (4) used in the official meat testing procedure for trichinosis is not a typical diagnostic method for the detection of alariosis in wild boar meat. A novel alternative based on differential detection of these parasites is the Alariamigration technique (AMT), based on the ability of mesocercariae to move actively from solid tissues into the surrounding liquid (warm water), as developed by German researchers. The differences between the methods lie in the sample type (connective and fatty tissue), the testing procedure (digestive solution) and the tools (a sieve) $(29,31)$. Despite these differences, the digestion method can still be used to detect Alaria trematodes, as evidenced in our own and other studies $(7,8,11,36)$.

The aim of the study was to assess the accuracy of the digestion method, a standard procedure for routine examination of wild boar meat for Trichinella, in detecting the presence of Distomum musculorum suis in the populations of wild boars from Eastern Lublin province.

\section{Material and methods}

The study material involved 500 meat samples collected from 500 wild boars (Sus scrofa). Half of the samples $(n=250)$ were collected from young animals (6- to 12-month-old piglets) and the other half from older individuals (subadults, young adults, boars, sows). The investigated animals were collected by hunters in the Eastern Lublin region during five hunting seasons in the years 2014-2019 (Fig. 2). From each animal, a $100 \mathrm{~g}$ sample of muscular tissue was collected from the pillars of the diaphragm.

The meat was first digested with hydrochloric acid and pepsin with the use of a magnetic stirrer, this being the reference method for detecting Trichinella (4). Each sample was digested individually using $50 \mathrm{~g}$ of meat and 1 liter of

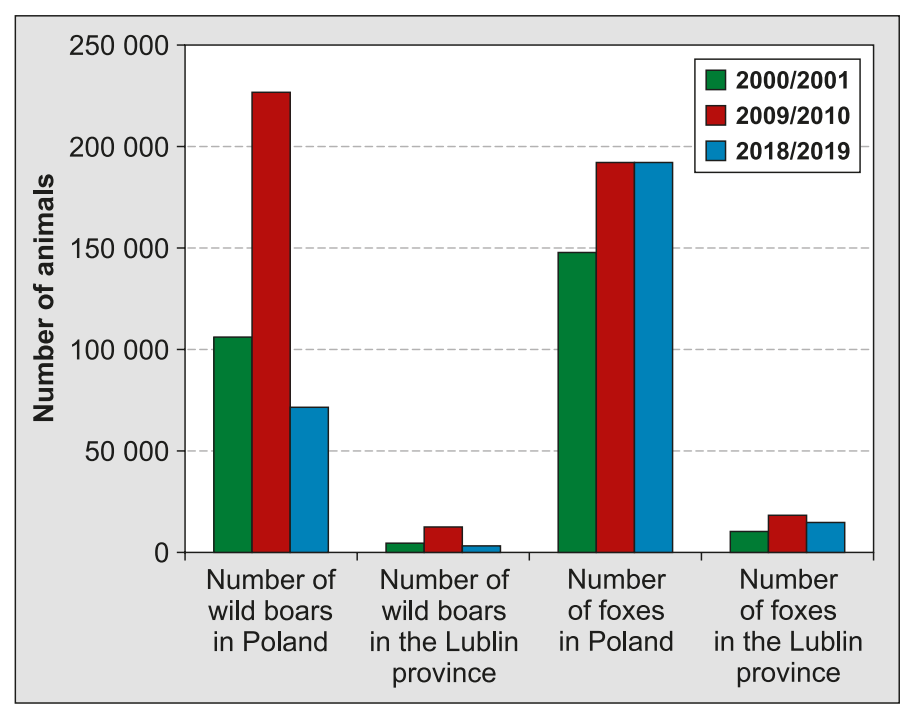

Fig. 1. The number of wild boars and foxes in Poland and the Lublin province in the years 2000-2009

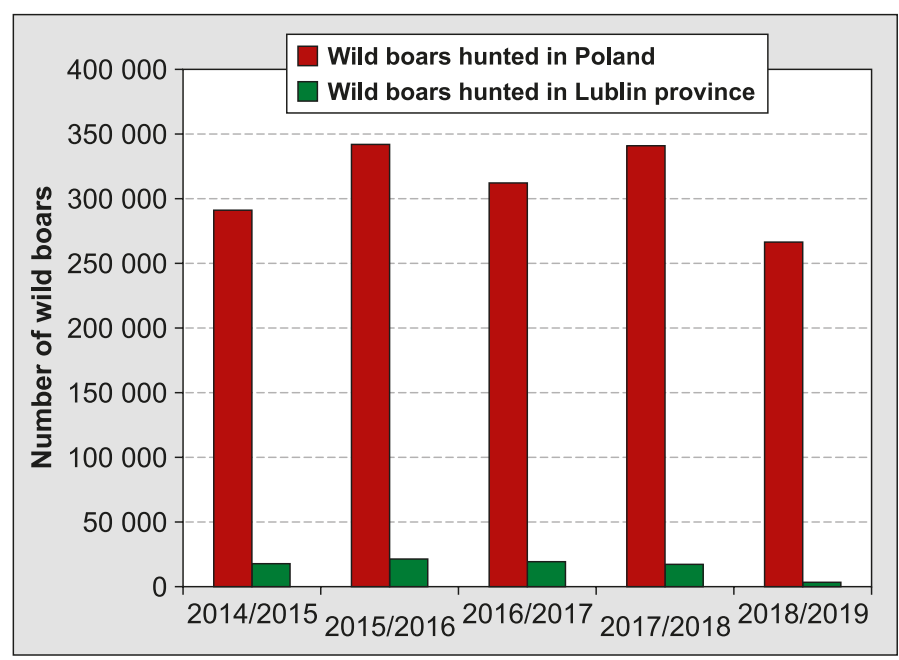

Fig. 2. Wild boars hunted in Poland and the Lublin province during five hunting seasons and used in the study

digestive solution. The digesting procedure was carried out on a magnetic stirrer at $44-46^{\circ} \mathrm{C}$ for 30 to $60 \mathrm{~min}$, depending on the animal age and according to the routine procedure of digesting wild boar meat. The digested liquid was then poured through a sieve and funnel into a separating funnel, where it was left for 30 minutes, this being the first sedimentation cycle. After this time, $40 \mathrm{ml}$ of the digested fluid was transferred into a graduated cylinder and left for $10 \mathrm{~min}$ for the second sedimentation cycle. Finally, $30 \mathrm{ml}$ samples of the supernatant were removed and the remaining $10 \mathrm{ml}$ of the sediment, along with $10 \mathrm{ml}$ of distilled water used for rinsing the cylinder, were poured into a counting basin. The trematodes were then counted under a projection trichinoscope at 15-20 times magnification or, if necessary, 60-100 times magnification.

In the next stage of the study, the boars whose samples yielded over 10 mesocercariae in $50 \mathrm{~g}$ of meat by the digestion method were then tested with the AMT method, designed for the detection of Distomum musculorum suis. Again, $50 \mathrm{~g}$ samples were collected from the same boar carcasses from the pillar of the diaphragm. The samples were finely cut with scissors into pieces of about $0.5 \times 0.5 \mathrm{~cm}$. 
Tab. 1. The presence of DMS in wild boars from the Eastern Lublin province depending on the animal age

\begin{tabular}{|c|c|c|c|}
\hline \multirow[b]{2}{*}{ Animal age } & \multicolumn{3}{|c|}{ Number $(\%)$ of wild boars tested with the digestion method } \\
\hline & Total & Positive results & $\begin{array}{l}\text { Positive results with over } \\
10 \text { mesocercariae in the sample* }\end{array}$ \\
\hline Young animals below 1 year (piglets) & 250 & $42^{\mathrm{a}}(16.8 \%)$ & $8^{\mathrm{a}}(3.2 \%)$ \\
\hline Animals older than 1 year (subadults, young adults, boars, sows) & 250 & $117^{\mathrm{b}}(46.8 \%)$ & $32^{b}(12.8 \%)$ \\
\hline
\end{tabular}

Explanations: * the samples in which the digestion method yielded over 10 parasite larvae were tested with AMT; a, b - difference significant in vertical direction for $\mathrm{p} \leq 0.05$

They were then placed on a metal mesh sieve in a glass funnel at $10 \mathrm{~cm}$ from its bottom. Warm water $\left(46-48^{\circ} \mathrm{C}\right)$ was then poured over the sample and allowed to naturally cool to room temperature. The samples were left for 90 minutes to allow mesocercaria migration and sedimentation from the samples. Following this, $10 \mathrm{ml}$ of the resulting sediment was poured into a graduated cylinder and, together with $10 \mathrm{ml}$ of distilled water used for rinsing the cylinder, transferred into a counting basin. The larvae were counted under a projection trichinoscope at 20 times or, if necessary, at 60-100 times magnification, similarly to the digestion method. The purpose of the second stage of the study was to compare the effectiveness of metacercariae detection by the digestion and AMT methods by identifying differences in the numbers of detected parasites.

The results were analyzed by calculating the mean values and the percentage of tested wild boars demonstrating a positive result. The influence of individual variability factors on the determined parameters was established by analysis of variance using the T-Tukey's multiple confidence interval test. Any relationships scoring $\mathrm{p} \leq 0.05$ were considered significant.

\section{Results and discussion}

Data on the presence of Distomum musculorum suis in wild boar meat obtained by the digestion method are presented according to age in Table 1.

Animal age was found to have a significant effect on the degree of parasitic infestation. Mesocercariae were present in 42 carcasses of animals below one year of age, known as piglets in hunting terminology, representing 16.8\% of the entire population from the investigated area. In the animals older than one year, called subadults, young adults, sows and boars, the parasite was detected in 117 samples, accounting for $46.8 \%$ of the studied population.

Our findings confirmed a high prevalence of Distomum musculorum suis in the population of wild boars from the Eastern Lublin Province. This high prevalence can be attributed to many factors and phenomena associated with the animal populations and the natural environment.
One significant factor is fox abundance, the final host of the parasite (Fig. 1); while its abundance varied significantly over the last twenty years, its numbers peaked from 2010 to 2017, coinciding with the study period. The special role played by foxes in the epizootic chain of alariosis has also been confirmed by other researchers $(12,36,38)$. Another factor potentially contributing to high incidence of the parasite in the investigated population was the high density of the animals in the study period (Fig. 1 and 2).

The biotope inhabited by the wild boar populations from the Eastern Lublin Province also seems to play an important role in the high prevalence of alariosis. The area can be described as a wetland abundant with swamps, peat bogs and water pools, and thus favorable for the development of water snails and frogs, known to act as intermediate hosts. A similar relationship between the infestation rate and the site of the sample collection has been confirmed by other Polish researchers. Bilska-Zając et al. (2) report an incidence rate of $4.2 \%$ in the southern Poland provinces of Małopolska and Śląsk; in addition, Strokowska et al. (35) report the rates from $26 \%$ in the Pomerania and Kujawy-Pomerania regions, through $49 \%$ in the Masovia region, up to $65 \%$ for the Warmia-Mazury region, which is dominated by wetlands.

Numerous authors $(7,11,24,30,32,38,25,22)$ have confirmed the presence of Alaria mesocercariae in

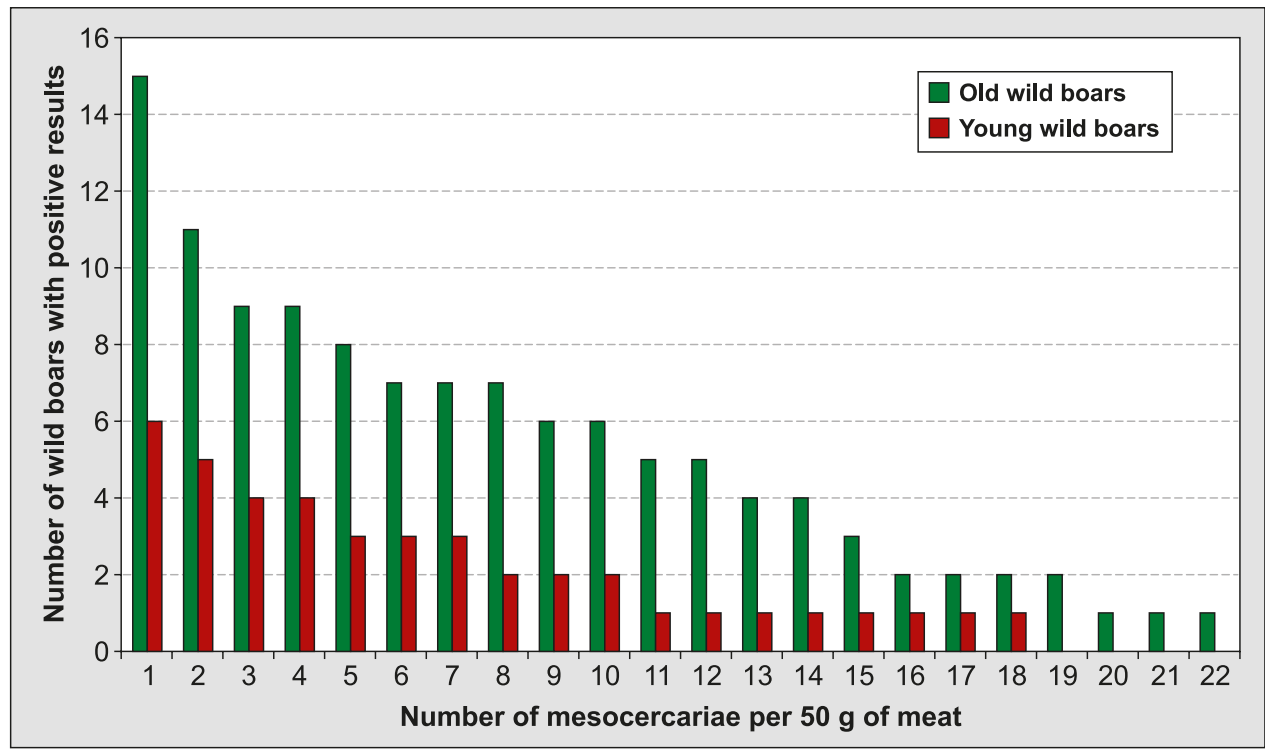

Fig. 3. The effect of wild boar age on the intensity of Alaria mesocercariae invasion detected by the digestion method $(n=500)$ 
many European populations of wild boar. As noted in the present study, the prevalence of the parasite infestation appeared to be linked with the animal habitat and the parasite identification method.

The intensity of Alaria mesocercaria invasion detected by the digestion method is presented in Figure 3. A range of intensities of parasite invasion were reported between individual animals. The intensities ranged from 1 to 18 per $50 \mathrm{~g}$ meat samples in young animals, and $1-22$ in older animals. Intensities of over 10 parasites per $50 \mathrm{~g}$ of

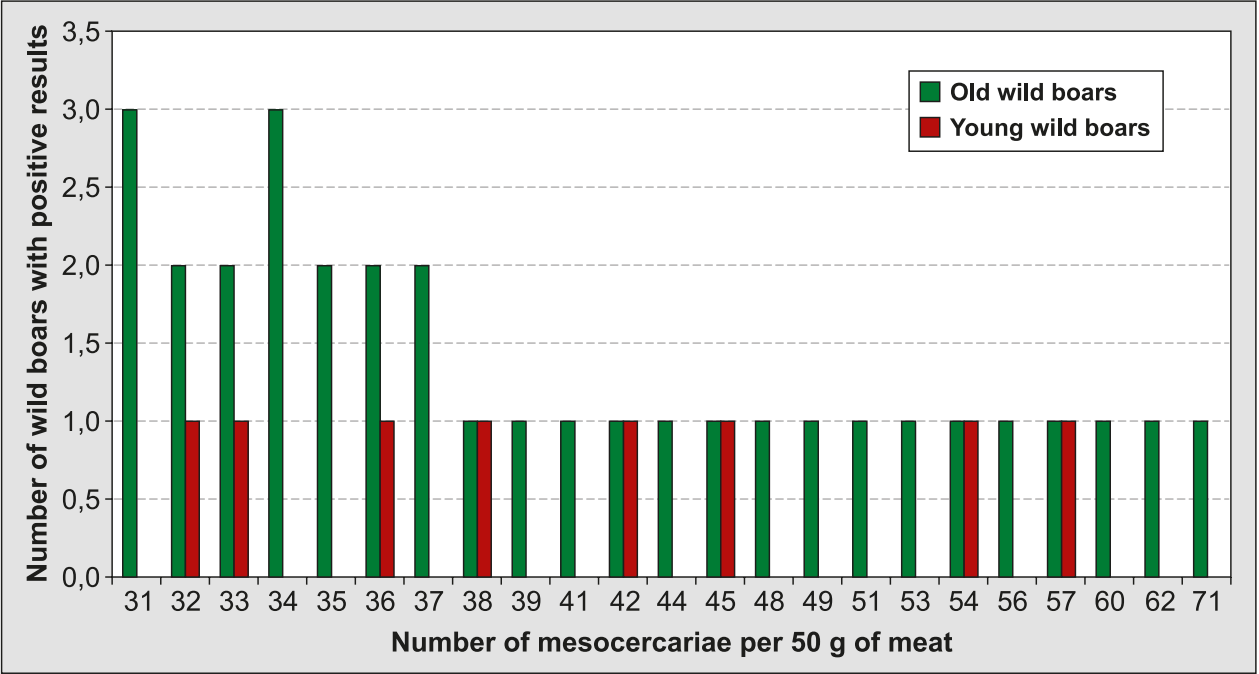

Fig. 4. The effect of wild boar age on the intensity of Alaria mesocercariae invasion detected by the AMT method $(n=40)$ $(3.2 \%)$ and 32 older (12.8\%) animals (Tab. 1$)$.

The results of the AMT testing performed in the samples collected from the animals where the digestion method revealed the presence of over 10 parasites are given in Figure 4. The findings also indicated that the intensity of the parasite infestation in $50 \mathrm{~g}$ meat samples varied considerably between carcasses, amounting to 32-57 individuals in young animals and 31-71 in the older ones. Similar high intensities of infestation with Alaria mesocercariae yielded by AMT method have also been confirmed by other authors $(2$, 20, 29, 31, 36).

Effectiveness of both methods is compared in Table 2 and Figure 5. Our study demonstrated almost three times higher efficiency of the AMT method than the digestion method. Similar conclusions were reached by Riehn et al. $(29,31)$ and Ozolina and Deksne (20), while Strokowska et al. (36) reported nearly seven times higher effectiveness of the AMT method in wild boars from the north-eastern Poland.

Our present study compared the effectiveness of the AMT and digestion method in only 40 samples: 32 older animals and eight younger ones. Of these, the latter demonstrated considerable rates of infestation by over 10 mesocercariae per $50 \mathrm{~g}$ of meat. In addition, the

two tested methods yielded substantial differences in the number of detected trematodes, ranging from 1 to 22 larvae in the digestion method, and from 31 to 71 in the AMT method. This confirms the huge diversity in the invasion intensity in individual animals.

Our experiments confirm that animal age plays a significant role in the prevalence of Alaria mesocercariae in wild boars; however, age did not appear to affect the intensity of the invasion (Tab. 1 and 2). The highest numbers of larvae detected in the $50 \mathrm{~g}$ meat samples are given in Figure 5. Our present find-

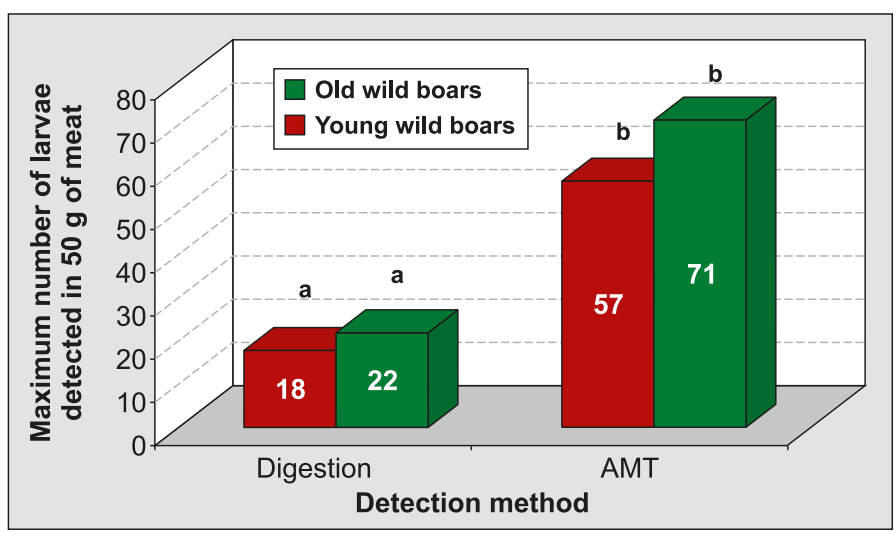

Fig. 5. Detection efficiency of Alaria mesocercariae depending on the testing method $(n=40)$

Explanations: $\mathrm{a}, \mathrm{b}$ - difference significant for $\mathrm{p} \leq 0.05$

Tab. 2. The presence of DMS in the carcasses ( $50 \mathrm{~g}$ samples) of wild boars from the Eastern Lublin province depending on the detection method and animal age

\begin{tabular}{|c|c|c|c|c|}
\hline \multirow[t]{2}{*}{ Compared parameters } & \multicolumn{2}{|c|}{ Digestion method } & \multicolumn{2}{|c|}{ AMT method* } \\
\hline & Young & Old & Young & Old \\
\hline Number of tested samples & 250 & 250 & 8 & 32 \\
\hline Number of positive samples & 44 & 117 & 8 & 32 \\
\hline Minimum number of larvae per sample & 1 & 1 & 31 & 32 \\
\hline Maximum number of larvae per sample & 18 & 22 & 57 & 71 \\
\hline Average number of larvae per sample & 7 & 6 & 14 & 15 \\
\hline Average number of larvae per sample where over 10 mesocercariae were detected ${ }^{*}$ & 14 & 15 & 42 & 42 \\
\hline
\end{tabular}

Explanations: * the samples in which the digestion method yielded over 10 parasite larvae were tested with AMT 
ings demonstrate that the digestion method is not an accurate method for detecting Alaria mesocercariae. This may be due to many factors based on the nature of the testing methods themselves. For example, the digestion method can detect Trichinella in skeletal striated muscle tissue (diaphragm, forearm, tongue or intercostal muscles), but is less sensitive for mesocercariae that prefer connective and fatty tissues outside of the muscles. As such, our results for the diaphragmatic samples should be considered high, as these did not take into account the connective and fat tissue from the same individuals. Furthermore, the sieve used in the digestion method has a high pore density and hence retains most of the larvae, and the digestive solution completely destroys the parasite structures in as little as 120 minutes, according to González-Fuentes et al. (9): Distomum musculorum suis does not have a hyaline sheath, the presence of which is used in the digestion test for Trichinella.

Our findings confirm a high incidence of Alaria mesocercariae in wild boars from the Eastern Lublin province, and they demonstrate the substantial role played by wild boars as a paretic host for this parasite. Considering the high number of wild boars hunted for human consumption, this poses a significant threat to food safety, as noted by other authors $(6,8,13,35)$. Numerous scientific reports $(1,6,13-15)$ indicate that the trematode has zoonotic potential. Due to this, and its high prevalence and invasion intensity, careful examination of wild boar meat for Alaria is needed to ensure its safety. Furthermore, it is recommended that food of animal origin be treated with thermal processing at a temperature ensuring parasite inactivation. These is also a need to implement mandatory, official procedures for detecting Alaria mesocercariae in Polish wild boars.

In summary, the trematode of Alaria genus is a parasite that attacks a range of wild and domestic carnivores, mainly foxes. It has a complex life cycle involving two intermediate hosts, and often also paretic hosts, among which can be wild boar (Sus scrofa). The presence of this parasite in wild boars is facilitated by the opportunistic behavior of the animals and their favoring of wetland habitats inhabited by the intermediate hosts. Many authors have documented the presence of alariosis in wild boars of numerous European regions depending on local environmental conditions.

Our study confirmed a high prevalence of the parasite among wild boars from the Eastern Lublin province and that the invasion intensity depended on the animal age, being higher in older individuals.

The standard method for detecting Alaria mesocercariae is the Alaria-Migration Technique (AMT) based on the parasite ability to migrate in warm water. Our tests confirmed that the AMT method is three times as sensitive as the digestion method, used for official examination of meat for Trichinella, in detecting
Alaria trematodes in wild boars. However, despite its many inadequacies, the digestion method can also be employed for the detection of Alaria mesocercariae in cases of abundant parasite infection. Considering the zoonotic nature of alariosis and its frequency, it poses an increasingly common problem for official veterinarians during the sanitary and veterinary evaluation of wild boar meat and when ensuring the safety of products derived from these animals.

\section{References}

1. Beaver P. C., Little M. D., Tucker C. F., Reed R. J.: Mesocercaria in the skin of man in Louisiana. Am. J. Trop. Med. Hyg. 1977, 26, 422-426.

2. Bilska-Zajac E., Marucci G., Piróg-Komorowska A., Cichocka M., Różycki M., Karamon J., Sroka J., Betcik A., Mizak I., Cencek T.: Occurrence of Alaria alata in wild boars (Sus scrofa) in Poland and detection of genetic variability between isolates. Parasitol. Res. 2021, 120, 83-91.

3. Bindke J. D., Springer A., Janecek-Erfurth E., Böer M., Strube C.: Helminth infections of wild European gray wolves (Canis lupus Linnaeus, 1758) in Lower Saxony, Germany, and comparison to captive wolves. Parasitol. Res. 2019, 118, 701-706.

4. Commission Implementing Regulation. EC No 2015/1375, Commission Implementing Regulation (EU) 2015/1375 of 10 August 2015 Laying Down Specific Rules on Official Controls for Trichinella in Meat. 2015.

5. Duncker H. C. J.: Die Muskel-Distomeen. Berl. Wschr. 1896, 24, 279-282.

6. Fried B., Abruzzi A.: Food-borne trematode infections of humans in the United States of America. Parasitol. Res. 2010, 106, 1263-1280.

7. Gavrilović P., Pavlović I., Todorović I.: Alaria alata mesocercariae in domestic pigs and wild boars in South Banat, northern Serbia. Comp. Immunol. Microbiol. Infect. Dis. 2019, 63, 142-144.

8. Gazzonis A. L., Villa L., Riehn K., Hamedy A., Minazzi S., Olivieri E., Zanzani S. A., Manfredi M. T.: Occurrence of selected zoonotic food-borne parasites and first molecular identification of Alaria alata in wild boars (Sus scrofa) in Italy. Parasitol. Res. 2018, 117, 2207-2215.

9. González-Fuentes H., Riehn K., Koethe M., von Borell E., Luecker E., Hamedy A.: Effects of in vitro conditions on the survival of Alaria alata mesocercariae. Parasitol. Res. 2014, 113, 2983-2989.

10. Górski P., Zalewski A., Lakomy M.: Parasites of carnivorous mammals in Białowieza primeval forest. Wiad. Parazytol. 2006, 52, 49-53.

11.Jaksic S., Unitil S., Vucemilo M.: Nachweiss von Mesozerkarien des Saugwurms Alaria alata im Wildschweinfleisch. Z. Jagdwiss. 2002, 48, 203-207.

12. Karamon J., Dąbrowska J., Kochanowski M., Samorek-Pieróg M., Sroka J., Różycki M., Bilska-Zając E., Zdybel J., Cencek T.: Prevalence of intestinal helminths of red foxes (Vulpes vulpes) in central Europe (Poland): a significant zoonotic threat. Parasites Vectors. 2018, 11, 436.

13. Korpysa-Dzirba W., Różycki M., Bilska-Zajac E., Karamon J., Sroka J., BetcikA., Wasiak M., Cencek T.: Alaria alata in Terms of Risks to Consumers' Health. Foods 2021, 10, 1614.

14. Kramer M. H., Eberhard M. L., Blankenberg T. A.: Respiratory symptoms and subcutaneous granuloma caused by mesocercariae a case report. Am. J. Trop. Med. Hyg. 1996, 55, 447-448.

15. McDonald H. R., Kazacos K. R., Schatz H., Johnson R. N.: Two cases of intraocular infection with Alaria mesocercaria (Trematoda). Am. J. Ophthalmol. 1994, 117, 447-455.

16. Miljević M., Bjelić Čabrilo O., Simin V., Čabrilo B., MiljevićJ. B., Lalošević D. Significance of the red fox as a natural reservoir of intestinal zoonoses in Vojvodina, Serbia. Acta Vet. Hung. 2019, 67, 561-571.

17. Möhl K., Grosse K., Hamedy A., Wuste T., Kabelitz P., Lucker E.: Biology of Alaria spp. and human exposition risk to Alaria mesocercariae - a review. Parasitol Res. 2009, 105, 1-15.

18. Murphy T. M., O'Connell J., Berzano M., Dold C., Keegan J. D., Mc Cann A., Murphy D., Holden N. M.: The prevalence and distribution of Alaria alata, a potential zoonotic parasite, in foxes in Ireland. Parasitol. Res. 2012, 111, 283-290.

19. Nugaraitè D., Mažeika V., Paulauskas A.: Helminths of mustelids with overlapping ecological Niches: eurasian otter Lutra Lutra (Linnaeus, 1758), American mink Neovison vison Schreber, 1777, and European polecat Mustela putorius Linnaeus, 1758. Helminthologia 2019, 56, 66-74.

20. Ozolina Z., Deksne G.: Effectiveness of two methods for mesocercariae of Alaria alata detection in wild boars (Sus scrofa). Envir. Experiment Biol. 2017, $15,25-28$. 
21. Ozolina Z., Bagrade G., Deksne G.: The host age related occurrence of Alaria alata in wild canids in Latvia. Parasitol. Res. 2018, 117, 3743-3751.

22. Ozolina Z., Deksne G., Pupins M., Gravele E., Gavarane I., Kirjušina M. Alaria alata mesocercariae prevalence and predilection sites in amphibians in Latvia. Parasitol. Res. 2021, 120, 145-152.

23. Patrelle C., Portier J., Jouet D., Delorme D., Ferté H.: Prevalence and intensity of Alaria alata (Goeze, 1792) in water frogs and brown frogs in natural conditions. Parasitol. Res. 2015, 114, 4405-4412.

24. Paulsen P., Forejtek P., Hutarova Z., Vodnansky M.: Alaria alata mesocercariae in wild boar (Sus scrofa, Linnaeus, 1758) in south regions of the Czech Republic. Vet. Parasitol. 2013, 197, 384-387.

25. Portier J., Jouet D., Ferté H., Gibout O., Heckmann A., Boireau P., Vallée I.: New data in France on the trematode Alaria alata (Göeze, 1792) obtained during Trichinella inspections. Parasite 2011, 18, 271-275.

26. Portier J., Jouet D., Vallée I., Ferté H.: Detection of Planorbis planorbis and Anisus vortexas first intermediate hosts of Alaria alata (Goeze, 1792) innatural conditions in France: molecular evidence. Vet. Parasitol. 2012, 190, 151-158.

27. Rentería-Solís Z. M., Hamedy A., Michler F. U., Michler B. A., Lücker E. Stier $N$., Wibbelt G., Riehn K.: Alaria alata mesocercariae in raccoons (Procyon lotor) in Germany. Parasitol. Res. 201, 112, 3595-3600.

28. Rentería-Solís Z., Kołodziej-Sobocińska M., Riehn K.: Alaria spp. mesocercariae in Eurasian badger (Meles meles) and wild boar (Sus scrofa) from the Białowieża Forest, north-eastern Poland. Parasitol. Res. 2018, 117, 1297-1299.

29. Riehn K., Hamedy A., Grosse K., Zeitler L., Lucker E.: A novel detection method for Alaria alata mesocercariae in meat. Parasitol. Res. 2010, 107 213-220

30. Riehn K., Hamedy A., Grosse K., Wuste T., Lucker E.: Alaria alata in wild boars (Sus scrofa, Linnaeus, 1758) in the eastern parts of Germany. Parasitol. Res. 2012, 111, 1857-1861.

31. Riehn K., Hamedy A., Saffaf J., Lücker E.: First interlaboratory test for the detection of Alaria spp. mesocercariae in meat samples using the Alaria spp. mesocercariae migration technique (AMT). Parasitol. Res. 2013, 112, 2653-2660 .

32. Sailer A., Glawisching W., Irschik I., Lucker E., Riehn K., Paulsen P.: Findings of Alaria alata mesocercariae in wild boar in Austria: current knowledge, identification of risk factors and discussion of risk management options. Wien. Tierärztl. Mschr. - Vet. Med. Austria 2012, 99, 346-352.

33. Shimalov $V$. V: Helminth infections of the brown rat (Rattus norvegicus Berkenhout, 1769) in the biocenoses of South-West Belarus. J. Parasit. Dis. 2017, 41, 599-601.

34. Shimalov $V$. $V$., Shimalov $V$. T.: Helminth fauna of the red fox (Vulpes vulpes Linnaeus, 1758) in southern Belarus. Parasitol. Res. 2003, 89, 77-78.

35. Strokowska N., Nowicki M., Klich D., Bełkot Z., Wiśniewski J., Didkowska A., Chyla P., Anusz K.: The occurrence of Alaria alata mesocercariae in wild boars (Sus scrofa) in north-eastern Poland. Int J Parasitol.: Parasites Wildlife 2020, $12,25-28$.

36. Strokowska N., Nowicki M., Klich D., Didkowska A., Filip-Hutsch K Wiśniewski J., Betkot Z., Anusz K.: A comparison of detection methods of Alaria alata mesocercariae in wild boar (Sus scrofa) meat. Int. J. Parasitol.: Parasites Wildlife 2021, 16, 1-4.

37. Szafrańska E., Wasielewski O., Bereszyński A.: A faecal analysis of helminth infections in wild and captive wolves, Canis lupus L., in Poland. J. Helminthol 2010, 84, 415-419.

38. Széll Z., Tolnai Z., Sréter T.: Environmental determinants of the spatial distribution of Alaria alata in Hungary. Vet. Parasitol. 2013, 198, 116-121.

39. Voelkel A. C., Dolle S., Koethe M., Haas J., Makrutzki G., Birka S., Lücker E., Hamedy A.: Distribution of Alaria spp. mesocercariae in waterfrogs. Parasitol. Res. 2018, 118, 673-676.

Corresponding author: Zbigniew Belkot, DVM, PhD, Department of Food Hygiene of Animal Origin, Faculty of Veterinary Medicine, University of Life Sciences in Lublin, Akademicka 12, 20-033 Lublin, Poland; e-mail: zbigniew.belkot@up.lublin.pl 